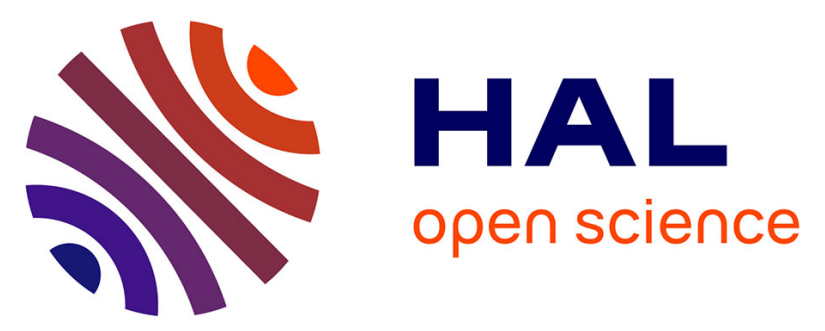

\title{
Combined Phonological Awareness and Print Knowledge Training Improves Reading Accuracy and Comprehension in Children with Reading Disabilities
}

Smail Layes, Mahmoud Guendouz, Robert Lalonde, Mohamed Rebai

\section{- To cite this version:}

Smail Layes, Mahmoud Guendouz, Robert Lalonde, Mohamed Rebai. Combined Phonological Awareness and Print Knowledge Training Improves Reading Accuracy and Comprehension in Children with Reading Disabilities. International Journal of Disability, Development and Education, 2020, pp.1-15. 10.1080/1034912X.2020.1779914 . hal-03220053

\section{HAL Id: hal-03220053 \\ https://hal.univ-lorraine.fr/hal-03220053}

Submitted on 6 May 2021

HAL is a multi-disciplinary open access archive for the deposit and dissemination of scientific research documents, whether they are published or not. The documents may come from teaching and research institutions in France or abroad, or from public or private research centers.
L'archive ouverte pluridisciplinaire HAL, est destinée au dépôt et à la diffusion de documents scientifiques de niveau recherche, publiés ou non, émanant des établissements d'enseignement et de recherche français ou étrangers, des laboratoires publics ou privés. 
Combined phonological awareness and print knowledge training improves reading accuracy and comprehension in children with reading disorders

Layes S., Guendouz M., Lalonde R., Rebai M.

\begin{abstract}
We examined the effects of a combined phonological and print intervention program on the enhancement of phonological awareness, text reading accuracy and comprehension in fourth grade Arabic-speaking children with severe difficulties in reading accuracy (dyslexia) and reading comprehension. We compared an experimental group $(n=22 ;$ mean age $=122.9$ months) to a control group ( $\mathrm{n}=22$; mean age $=124.65$ months). The training program focused on two domains: phonological awareness and print knowledge. The results showed that the experimental group performed better in the post and follow-up assessments than in baseline assessment on phonological awareness, reading accuracy, and comprehension. We discuss findings indicating the positive impact of phonological awareness and print knowledge on reading development in terms of decoding and comprehension abilities.

Keywords: Combined training, phonological awareness, print knowledge, reading accuracy, reading comprehension.
\end{abstract}




\section{Introduction}

The two most common aspects among reading development disorders are dyslexia, a specific learning disability characterized by inaccurate decoding, and reading comprehension impairment (Lyon, Shaywitz,\& Shaywitz, 2003; Snowling \&Hulme, 2012). Reading development not only involves the acquisition of accurate and fluent word decoding but also the acquisition of reading comprehension. Thus, the process of reading comprehension goes beyond decoding and requires not only the access to the meaning of single words but also the meaning of written language at the sentence or text level (Hoover \& Gough 1990). Reading comprehension is a complex process that depends on oral language and reading skills and typically with reading accuracy. A substantial body of research examining the neurocognitive basis of developmental dyslexia shows word decoding and recognition to be the locus of difficulty and the strongest predictor of reading comprehension (Pennington, 1991). Therefore, reading developmental disorders require particular attention focused on interventions strategies designed to improve difficulties in decoding and reading comprehension (Snowling \&Hulme, 2011).

Although children with dyslexia are defined by their reading inaccuracy and decoding difficulties, some have problems with reading comprehension unrelated to an underlying oral language disorder (Shaywitz, Morris, \& Shaywitz, 2007). Rather, they are attributable to slow and inaccurate word reading, leaving few attentional resources available for comprehension. However, reading comprehension impairments can occur in the absence of poor decoding, suggesting that it is a distinct disorder (Snowling, 2013). Research has shown that a relatively large group of readers show problems with reading comprehension despite fluent word decoding. This group often called poor comprehenders, has been estimated at $10-15 \%$ of children aged 7-10 years (Cain \& Oakhill, 2007; Hulme \& Snowling, 2011). The distinction between dyslexia and reading comprehension impairment is consistent with the simple view of reading (Gough \& Tumner, 1986), according to which reading comprehension is the product of decoding and listening comprehension. Thus, three kinds of poor readers have been identified: those with poor decoding (dyslexia), those with poor listening comprehension (poor comprehenders), and those with impairments in both (Snowling, 2013).

The core of reading and reading difficulties that has attracted much attention over the last two decades is phonological awareness (PA) (e.g. Torgesen \& Mathes 2000). PA refers to an individual's implicit and explicit sensitivity to the sub-lexical structure of oral language. Additional indicators of the advent of PA include word awareness (understanding that sentences contain words) and syllable awareness (understanding that words comprise 
syllables). A lack of this awareness may impede an individual's ability to acquire accurate and fluent word reading skills, and, as such, is a primary source of difficulty for children with reading disabilities across languages (Lyon et al., 2003; Vellutino, Fletcher, Snowling, \& Scanlon, 2004), including Semitic languages such as Arabic (Abu-Rabia, Share, \& Mansour, 2003; Saiegh-Haddad, 2007). The primary difficulty with word recognition in children with developmental dyslexia is related to a deficit in encoding phonologically the translation of sub-vocal units of print into sound, making reading less automatic and thus interfering with reading comprehension. Problems with slow and inaccurate word reading can impede adequate reading comprehension. It follows that dyslexia can be associated with poor reading comprehension, but this is by no means inevitable.

Although PA is necessary to the development of skilled decoding, it is insufficient for acquiring the ability to read words (NRP, 2000). Instead, decoding development is initiated by PA in combination with print knowledge (Stuart \& Coltheart, 1988). Two major domains of emergent literacy were identified as important predictors of reading ability: PA, which require direct instruction, and print awareness (knowledge), learned primarily by experience prior to systematic literacy instruction (NRP, 2000). Print knowledge is an umbrella term that encompasses children's concepts of print and their alphabetic knowledge. This term typically refers to one's understanding of the forms and functions of written language and of letters and their corresponding sounds (Justice, Bowles \& Skibbe, 2006).

Although print knowledge has a reciprocal relationship with PA, there is evidence that it represents a separate construct (Lonigan, Burgess, \& Anthony, 2000). Each construct uniquely predicts later reading competency, indicating that a deficit in either may put a child at risk for limited literacy achievement (Catts, Fey, Zhang, \& Tomblin, 2001). Jones, Clark and Reutzel (2013) stated that students' knowledge of the names, sounds, and symbols of the letters or alphabetic knowledge is essential for learning to read and write. Skills related to print knowledge (i.e. alphabet knowledge, concepts about print, etc.) were moderate to strong predictors of all conventional literacy skills.

As the phonological deficit theory has been widely considered in recent years, the development of training programs has focused primarily on this component for children with reading disability (Defior, 2008; Jiménez \& Ortiz, 2000). However, PA based interventions are specifically designed to improve PA and decoding, but its impact on reading comprehension deserves full consideration (Snowling \& Hulme, 2012 ). Several studies concerned with consistent orthographies suggest that PA plays an important role not only in the development of basic reading skills, but also in reading comprehension throughout 
primary school ages. Engen and Høien (2002) examined the role of PA on reading comprehension in a large sample of children from Grade 1 . The results showed that in both average and poor decoders, PA had a direct impact on reading comprehension, indicating that phonological factors play an independent role in reading. According to the authors, vocabulary and short-term memory factors are both determined in part by phonological ability. However, it is unclear whether this positive impact of PA training goes through the improvement of reading accuracy (word recognition) or not and whether such a training program includes, and to what extent, print knowledge components such as letter knowledge.

Research workers advocate that effective training programs should include explicit instruction in PA skills, including the connection between sound and print (Lundberg, Frost \& Petersen, 1988). This suggests that intervention programs that have utilized training of sounds and letters simultaneously have produced larger gains than training PA alone (Ball \& Blachman, 1988). Meta-analytic studies on the effects with preschool and older children suggest that PA interventions that include those involving print have larger effects than PA interventions alone (Bus \& van Ijzendoorn, 1999; Ehri, Nunes, Willows, et al., 2001).

To date, the preponderance of awareness training studies have focused on word-level reading, and were repeatedly found to play an important role in word reading across different orthographies (e.g., O'Connor, Harty, \& Fulmer, 2005). Only a few studies have to do with the effects of PA combined with print training in children with reading decoding and comprehension disabilities (Sénéchal, Ouellete, Pagan, \& Lever, 2012). Based on the lack of such combined training for Arabic speaking children with reading disabilities, the intervention program in the current study comprises different components, such as training in PA including grapheme-phoneme decoding, and print knowledge including letter knowledge to enlarge the potential effects to both reading accuracy and comprehension.

The major goal of the present study was to investigate, whether PA training is an effective intervention to improve reading accuracy in Arabic fourth graders with reading accuracy and comprehension disorders, and whether these children can equally benefit from this program to improve reading comprehension. The research questions raised are: does combined PA and print knowledge training produce measurable effects on reading accuracy? Are such effects replicated on reading comprehension?

\section{Method}

\section{Participants}

Participants were initially recruited as poor readers $(n=77)$ based on teachers' opinions. Quick screening was performed using Raven's colour matrices for word and 
pseudo-word reading test to exclude cases failing to meet diagnosis criteria. Afterwards, we eliminated 14 cases whose profiles did not match the exclusive criteria detailed below; we included 63 children diagnosed with dyslexia based on at least -1.5 SD below the standardized score of their age as well as word and pseudo-word reading accuracy. After the reading comprehension test was administered, only subjects having -1 below the mean were retained for the purpose of this study $(n=44)$. This process was necessary to ensure that all participants had both reading accuracy and comprehension deficiencies. We divided participants equally into two groups following a randomized design in which children were assigned to each condition individually: an experimental group $(n=22)$ with a mean age of 122.68 months (SD $=5.79)$ and a control group $(\mathrm{n}=22)$ age 123.82 months $(\mathrm{SD}=3.82)$. Independent $\mathrm{t}$ tests showed no differences between the two groups on age and Raven scores (Table 1). All participants were native Arabic speakers exposed to standard Arabic in regular classes and exempt from any oral language disability, history of hearing or visual impairment, and any developmental disorder such as hyperactivity.

\section{Materials}

\section{Non-verbal mental ability}

Raven's Standard Progressive Matrices is a nonverbal test of reasoning ability and general intelligence. We used the shortened form comprising 36 items (Sets A, B, and C) and consisting of a target matrix with one missing part. The children selected from six to eight alternatives to fill the missing patch.

\section{Word reading test}

The reading test consisted of a set of 80 stimuli ( 40 frequent words and 40 infrequent words) varying in length (di-syllabic and tri-syllabic) and frequency of usage (high and low) in addition to a list of 20 pseudo-words varying in orthographic length (Authors, 2014; Authors, 2015, 2017, 2019). A set of 20 stimuli per list was given, frequent words and infrequent words. A list of 40 pseudo-words varied in orthographic length (CVCV/CVCVC), whereas 20 items were derived from real words by altering the position of two letters, the other 20 pseudowords were randomly composed by consonants and vowels with no existing root in the Arabic language. Participants were required to read aloud the item correctly without any time limit. Scores included total number of words correctly read. The internal consistency reliability was $\alpha=.89$.

\section{Reading comprehension test}

This test was designed to evaluate reading accuracy and comprehension in children of the $4^{\text {th }}$ grade (Athors, 2005). The text was a short story that narrates well known events and 
was divided into three paragraphs, each consisting of three to four lines. The text was elaborated from a textbook of grade 3 and 4 that may ensure its appropriateness for the participants and includes familiar and non-familiar words (Zwobada, 1978). The text consisted of 125 words measuring the reading accuracy and six questions that measure reading comprehension. Linguistic categories of the words include: relationships (e.g. with, behind), action verbs (e.g. take), abstract verbs (e.g. want), familiar and unfamiliar vocabulary. Participants were instructed to read the text aloud clearly and as accurately as possible. The text was presented individually without prior time limit. The child had the possibility of self-correction and was encouraged to continue even if he/she finds it difficult.

A content validity test was done with Pearson's product moment correlations between the three paragraphs and the total score of reading accuracy (ranging from 0.72 and .77), considered as acceptable values. Based on a sample of 20 students, the test-retest reliability of reading accuracy was $\mathrm{r}=.83$ and $\mathrm{r}=.81$ for reading comprehension.

Phonological awareness: syllable blending task

The purpose of the phonological blending task was to measure the child's ability to blend syllables together to form a word when syllables were extracted from orally presented words. Twenty series of three words each were presented orally one at a time, and participants were instructed to isolate the initial syllable from each word and pronounce the new combination, producing a new word (Authors, 2017). The examiner paused for $3 \mathrm{sec}$ between words. The child was to respond with the target word without pausing or altering the pronunciation or order of presentation of the syllables. Each child was given three practice items prior to the administration of the test items. The child's score was based on the total number of correct responses on the test items only when giving the correct target word. The test-retest reliability of this task was $r=.71$.

\section{Phonological awareness and print knowledge intervention}

As reviewed, it is widely established that poor decoding hinders the process of understanding in many children with word recognition problems. Therefore, an intervention to promote the development of word level decoding skills is entirely needed (Pullen \& Justice, 2003). The central goal of this study was to improve performance in PA with direct implications for print knowledge as two intertwined skills underlying the reading processes. Based on previous phonological training studies for Arabic-speaking children (Authors, 2015; 2019), this intervention program was designed to improve children's awareness of the sound structure of spoken language focusing on phoneme manipulation and segmenting, and to develop their conscious knowledge of the links between the spoken form of print (letters, 
syllables, and words) and its written representations. Blending and segmenting activities have been shown to improve the skills of children with low PA (O’Connor, Jenkins, \& Slocum, 1995).

The key principles that formed the basis for the program content and implementation procedure focus on the development of the phonemic level (Brady et al., 1994) integrated with letter-sound knowledge (Hatcher, Hulme, \& Ellis, 1994), with particular attention given to segmentation abilities (Torgesen et al., 1992). Furthermore, the combinations of letter knowledge and letter-sound associations with PA activities may engage children to reflect deeply on the print code (Cunningham, 1990). The main components of the training program designed to promote word level decoding and text comprehension, associate training in PA with training in letter-sound knowledge linked with the concepts of print knowledge, i.e. directionality, awareness of word, syllables and letters. Such an approach goes beyond the abstract phonic level by ensuring that children have adequate PA skills experienced in context (Snowling \& Hulme, 2012).

The order of the activities in this program is based on the well-established acknowledgment that PA is a multi-level skill that involves the segmentation of words into increasingly smaller linguistic units, i.e. from syllabic to sub-syllabic units (Anthony, Lonigan, Driscoll, Phillips, \& Burgess, 2003). The program provides two main training units where the activities are sequenced in a pseudo-hierarchical order. Each of the units predominantly consists of a variety of unit sizes from short vowels to letters, syllables and words. The main program content and activities are:

1. Phonological awareness

- Identification of the first phoneme in words presented orally then by images

- Identification of images whose names share the same first phoneme

- Word segmentation into syllables (orally presented then illustrated by images)

- Phoneme deletion and presentation of the remaining segment of the word

- Graphemic sequence segmentation into meaningful words

- Syllable repetition supported with hand movements

- Segmentation of words into syllables

3. Print knowledge: includes:

\subsection{Letter Knowledge}

- letter names and sounds

- letter counting in words and association with the corresponding sounds 
- letter identification based on form and sound similarities

- letter identification in the word

- categorizing pictures by the initial sound in the word

\subsection{Word processing}

- Letter position manipulation: reordering the letters in the word for creating a new one

- supplementing the missing letter in the word

- corresponding images-words association

\section{Design and procedure}

All participants were tested individually on a Raven and word and pseudo-word reading tests. This testing took place after consent was received from parents informed about the general aim of the study but before participants were tested. Following a pre-test/post-test experimental design, we randomly assigned participants to the group that received the phonological training program (experimental group) or to the comparison group that did not receive the training (control group) after collecting baseline assessment data.

The training sessions involving face-to-face interactive training took place in a quiet room inside a school building but outside of regular classroom hours over a period of 13 weeks. The program was implemented collectively in small groups of 11 participants each following intensive small group service delivery (Torgesen, Wagner, \& Rashotte, 1994), and the activities were executed individually to be mastered within several times if necessary. There were two sessions per week for each sub-group, with each training session lasting approximately $50 \mathrm{~min}$. The participants received a detailed description of each task session and then provided responses individually following the specific instruction of the task. We moved throughout the program content as indicated above. If $\geq 80 \%$ of trained activity had been performed accurately, the next training activity was administered.

Pre-training and post-training comparisons were performed for both groups to check for potential improvement over times. To evaluate the effectiveness of the program, two posttraining measurements were applied for both groups within the same periods, post-training and follow-up assessments. After data collection in the pre-training period, both groups received regular lessons in school. The follow-up assessment was implemented 3 months after the post-training assessment.

\section{Results}

The major goal of the present study was to investigate whether combined PA and print knowledge intervention is effective to improve significantly PA in children with severe 
difficulties in reading accuracy (dyslexia) and comprehension and whether these children can equally benefit from this training in reading accuracy and comprehension. Pre-intervention comparisons between the two groups with independent-sample $t$ tests are shown in Table 1. Results revealed statistically significant intergroup differences on PA, reading accuracy in post and follow-up assessments in the experimental group. However, reading comprehension showed a significant improvement only on follow-up.

Table 1

To examine mean differences between the three times of assessment regarding the group variable, we performed two-way (group x times) repeated analysis of variance (ANOVA) for the outcome variables (PA, reading accuracy and reading comprehension) separately (see Table 2 and Figure 1). The statistical analysis (output 1) yielded a significant main effect for PA $\left[\mathrm{F}(2,41)=5.70, \mathrm{p}=.007\right.$, Wilks' $\left.\mathrm{Lambda}=.782, \eta p^{2}=.21\right]$ along with a significant interaction between factor and group $[\mathrm{F}(2,41)=4.14, \mathrm{p}=.02$, Wilks' Lambda $\left.=.832, \eta p^{2}=.16\right]$, a significant main effect for reading accuracy $[\mathrm{F}(2,41)=9.94$, $\mathrm{p}=.000$, Wilks' Lambda $=.673, \eta \mathrm{p}^{2}=.327$ ] along with an interaction between factor and group $\left[\mathrm{F}(2,41)=4.58, \mathrm{p}=.01\right.$, Wilks' $\left.\operatorname{Lambda}=.817, \eta \mathrm{p}^{2}=.18\right]$, and a main effect for reading comprehension $\left[\mathrm{F}(2,41)=4.25, \mathrm{p}=.02\right.$, Wilks' Lambda $\left.=.828, \eta p^{2}=.172\right]$ along with with an interaction between factor and group $[\mathrm{F}(2,41)=5.61, \mathrm{p}=.007$, Wilks' Lambda $=.785$, $\left.\eta p^{2}=.215\right]$.

Table 2 here

Figure 1 here

\section{Discussion}

We examined the effects of a combined phonological and print intervention program on PA, reading accuracy, and comprehension in $4^{\text {th }}$ grade Arabic speaking children with reading accuracy and comprehension disorders. The main finding was that the experimental group benefited from the program in terms of directly improved PA and reading accuracy. Training also had an impact on reading comprehension, which persisted for a considerable amount of time after program implementation.

With respect to the first research question regarding the potential positive impact of the intervention program on PA and reading accuracy, children who received the intervention program outperformed the control group on PA and reading accuracy. Intra-group comparison showed that the experimental group performed better in post- and follow-up intervention assessments (T2 and T3) than in the pre-assessment (T1). The most potent effect occurred for 
PA, assessed by the blending phoneme test through both post-measurement times. In this combined phonological and print training, the explicit practice of grapheme-phoneme association and the segmentation of words into syllables were taught repeatedly. Positive effects of the intervention program replicate previous investigations in Swedish (Fälth, Idor, \& Tomas, 2011), English (Snowling \& Hulme, 2011), and Arabic (Dallasheh-Khatib, Ibrahim, \& Karni, 2014), demonstrating that acquired awareness of word structure is related to reading performance across languages. Likewise, in numerous studies on kindergarten children, blending and segmenting activities improved the skills of children with low PA on PA tasks and on a reading task (O’Connor, Jenkins, \& Slocum, 1995; Torgesen, Morgan, \& Davis, 1992). Our results showed that PA had slightly greater improvement in T3 than in T2 in the experimental group, indicating that more PA instructions potentiates reading accuracy, which in turn can boost PA development, as many authors have argued that there is a bidirectional influence between PA and reading (e.g. Wagner, Torgesen, \& Rashotte, 1994). Awareness of the sub-lexical structure of oral language may promote students' reading development as well as their sensitivity to phonemes. In turn, an awareness of phonemes will increase rapidly while learning to read (Goswami, 1999).

By the end of the intervention program, better reading accuracy suggests that the intervention helped them identify efficiently the internal phonological structure of words, leading to more precise mapping of sounds to letters and targeting the awareness of individual sounds (phonemes) in the words (Ehri et al., 2001). The intervention seems to improve not only PA typically observed in children with reading disability but also text reading accuracy. The improvement in PA may lead to improved reading accuracy in dyslexic children who benefited from the phonological training program, in line with previous findings in Arabic (Authors, 2019). The authors examined the potential impact of phonological training on enhancing phonological processing and word and pseudo-word reading in children with dyslexia. All post-training measures for reading words and pseudo-words as well as phonological processing improved. It is likely that the practice and the repeated exposure of grapheme-phoneme correspondences become consolidated into larger units that are easily activated when read (Ehri, 2005). Al-Otaiba, Kosanovich and Torgesen (2012) argued that PA helps children understand the alphabetic principle and develops alphabetic knowledge. It also helps children notice the systematic ways that letters represent sounds of words allowing them to decode even unfamiliar words.

The second research question addressed a potential improvement in reading comprehension as a result of enhanced PA and reading accuracy. By the end of the 
intervention program, findings revealed a positive impact on reading comprehension performance at T3, though not at T2. Participants in T2 may not have been fluent enough in decoding. During the period following the intervention program, children were likely to be more able to apply constantly the acquired knowledge in PA and print knowledge, leading to a growing ability in decoding and word recognition. This would allow children to acquire more decoding automacity and reading fluency.

Cognitive psychologists have highlighted the important link between word analysis fluency and comprehension (Chafouleas, Martens, Dobson, Weinstein, \& Gardner, 2004). A comprehensible explanation was outlined by Perfetti (1985) in the bottle-neck theory of automaticity. It states that within a limited capacity system, decoding skills must be automatized such that capacity can be allocated to higher-order level processes necessary for successful reading comprehension. It is well established that fluent reading allows expending less mental effort in identifying words to apply more effort in understanding the text more thoroughly. Proficiency regarding fluency is one of the most powerful indicators of successful reading and obtaining meaning (Fuchs, Fuchs, Hosp, \& Jenkins, 2001).

Snowling \& Hulme (2012) found that children who received the combined program (phonology with reading) were significantly ahead of the other group who received the phonology alone for reading accuracy, spelling, and reading comprehension. The gains in reading were maintained 5 months after the intervention ended. The authors asserted that those findings challenged the theory that phonological deficits alone cause reading impairment, since it was only when PA was trained in orthography that the impact on reading was significant. Similarly, Müller, Richter, Karageorgos, Krawietz, \& Ennemoser (2017) examined a syllable-based word recognition intervention for German fourth graders with reading difficulties. Basic word reading skills were administered followed by testing the effects of this training on the efficiency of written word recognition and the potential transfer effects on reading comprehension skills at the text level. Quels sont les résultats?

The positive impact of PA training on reading comprehension in our study is consistent with findings in languages with transparent orthography, suggesting that PA plays an important role in the development of reading comprehension throughout primary schooling (e.g. Schiffn Schwartz-Nahshon, Nagar, 2011), perhaps mediated by the effect of PA on decoding. This is in line with the result of a study that explored the impact of PA on reading comprehension in 1300 Norwegian first graders (Engen \& Hoien 2002). The study involved syllable awareness, phoneme awareness, word decoding, and reading comprehension. PA had a direct impact on reading comprehension above the indirect phonological effect mediated by 
decoding skills, indicating that phonological factors play an independent role in processing text. They proposed that the direct effect of PA on reading comprehension is due to the fact that PA is related to other skills such as vocabulary knowledge and short-term memory, both determined in part by phonological ability. PA might partly reflect metacognitive processes assumed to be involved in reading comprehension. The findings of this study indicate that children who have better abilities in analyzing and manipulating syllables and phonemes with the ability to identify words and their inflected or derived forms are better at learning to read than children who have difficulties in acquiring these skills.

The improvement in reading comprehension seen in our study may also be mediated by morphological awareness as a direct impact of the intervention program. Indeed, Authors (2015) showed that PA training produced significant gains in morphological awareness in an Arabic dyslexic cohort. The ability to manipulate the sound structure of words facilitated the development of morphological awareness and highlights a reciprocal relation between the faculty and PA, though scores of each contributed an independent part of the variance found in word reading. In Arabic, morphological awareness involves the ability to identify word roots and their inflected or derived forms to understand the structure and meaning of a word and the different combinations of its morphemes. Indeed, the contribution of morphological awareness to reading comprehension may occur via accurate and rapid reading of words, enabling individuals to analyze the internal structure of words and decode them more quickly and accurately (Deacon \& Kirby, 2004; Nagy, Berninger, \& Abbott, 2006).

\section{Conclusions}

The present study demonstrated that combined PA and print knowledge training can be an effective intervention to improve reading accuracy and comprehension in Arabic speaking children fourth graders with reading accuracy and comprehension disorders. A follow-up assessment was suitable to demonstrate maintenance effects on reading skills (e.g., Castles \& Coltheart, 2004). Although PA training is widely carried out across languages, this is the first set of data to demonstrate both direct and transfer effects of a combined phonological and print knowledge intervention in Arabic speaking children. Improvements in PA enabled children with reading accuracy disorder to decode words (Share, 1995), allowing them to access a greater amount of information in the written text. These findings support the view that dyslexia is mainly related to a phonological deficit, manifested in problems with PA and emphasize the importance of establishing phonological representations of phonemes and print in reading Arabic (Asaad \& Eviatar, 2014; Saiegh-Haddad, 2005). 
Our findings add evidence to studies in other languages concerning the impact of combined phonological training on reading proficiency, addressing several subskills at the phonologic and print levels and pointing to the contribution of such training in facilitating the development of PA in children with reading disabilities (e.g., Høien-Tengesdal \& Tønnessen, 2011). Findings of the current study have important practical implications. Practitioners and teachers need to know whether PA and print knowledge tasks are necessary for children in primary school. Accordingly, better understanding of the effects of PA and print knowledge may help in basic reading skills and early screening of children at risk for reading disabilities (Wagner et al., 1997).

\section{References}

Abu-Rabia S., Share D., Mansour M. A. (2003). Word recognition and basic cognitive processes among reading-disabled and normal readers in Arabic. Reading and Writing, $16423-442$.

Al Otaiba, S., Kosanovich, M. L., \& Torgesen, J. K. (2012). Assessment and instruction in phonemic awareness and word recognition skills. In A. G. Kamhi, \& H. W. Catts (Eds.), Language and reading disabilities (pp. 112-114). Upper Saddle River: Pearson Education Inc

Anthony, J., Lonigan, C., Driscoll, K., Phillips, B., \& Burgess, S. (2003). Phonological sensitivity: A quasi-parallel progression of word structure units and cognitive operation. Reading Research Quarterly, 38, 470-487.

Asaad, H., \& Eviatar, Z. (2014). Learning to read in Arabic: The long and winding road. Reading and Writing, 27, 649-664.

Ball, E., \& Blachman, B. (1988). Phoneme segmentation training: Effect on reading readiness. Annals of Dyslexia, 38, 208-225.

Brady, S., Fowler, A., Stone, B. \& Winbury, N. (1994). Training phonological awareness: A study with inner-city kindergarten children. Annals of Dyslexia, 44, 26-58.

Bus, A. G., \& van Ijzendoorn, M. H. (1999). Phonological awareness and early reading: A meta-analysis of experimental training studies. Journal of Educational Psychology, 91, 403-414.

Cain K., \& Oakhill J. (2007). Reading comprehension difficulties: Correlates, causes, and consequences. In Cain K. \& Oakhill J. (Eds.), Children's comprehension problems in oral and written language (pp. 41-75). New York: Guilford Press. 
Castles, A., \& Coltheart, M. (2004). Is There a Causal Link from Phonological Awareness to Success in Learning to Read. Cognition, 91, 77-111.

Catts, H.W., Fey, M. E., Zhang, X., Tomblin, J. B. (2001). Estimating the risk of future reading difficulties in kinder-garten children: A research-based model and its clinical implementation. Language, Speech, and Hearing Services in Schools, 32, 38-50.

Chafouleas, S. M., Martens, B. K., Dobson, R. L., Weinstein, K. S., \& Gardner, K. B. (2004). Fluent reading as the improvement of stimulus control: Additive effects of performance-based interventions to repeated reading on students' reading and error rates. Journal of Behavioral Education, 13, 2, 67-81.

Cunningham, A. (1990). Explicit versus implicit instruction in phonemic awareness. Journal of Experimental Child Psychology, 50, 429-444.

Dallasheh-Khatib, R., Ibrahim, R., \& Karni, A. (2014). Longitudinal data on the relations of morphological and phonological training to reading acquisition in first grade: The case of Arabic language. Psychology, 5(8), 918-940. doi:10.4236/psych.2014.58103

Deacon S.H., \& Kirby, J.R. (2004). Morphological awareness: just "more phonological"? The roles of morphological and phonological awareness in reading development. Applied Psycholinguistics, 25, 223-238.

Defior, S. (2008). How to facilitate initial literacy acquisition: the role of phonological skills. Infancia Aprendizaje, 31, 333-345. 10.1174/021037008785702983

Ehri, L. (2005). Development of sight word reading: Phases and findings. In Snowling, M., Hulme, C. (Eds.), The science of reading: A handbook (pp. 135-154).

Ehri, L. C., Nunes, S. R., Stahl, S. A., \& Willows, D. M. (2001). Systematic phonics instruction helps students learn to read: Evidence from the National Reading Panel's meta-analysis. Review of Educational Research, 71, 393-447.

Ehri, L.C., \& Nunes, S.R. (2001) Systematic phonics instruction helps students learn to read: evidence from the national reading panel's meta-analysis. Journal of Direct Instruction , 2 ( 2), 121-166.

Ehri, L.C., Nunes, S. R., Willows, D. M., Schuster, B., Valeska Y.-Z. Z., \& Shanahan, T. (2001). Phonemic awareness instruction helps children learn to read: evidence from the National Reading Panel's meta-Analysis. Reading Research Quarterly, 36, 3, 250 287

Engen, L., \& Høien, T. (2002). Phonological skills and reading comprehension. Reading and Writing: An Interdisciplinary Journal, 15, 613-631. 
Fälth, L., Svensson, I., \& Tjus, T. (2011). The effects of two training programs regarding reading development among children with reading disabilities. Psychology, 2, 173180.

Fuchs, D., Fuchs, L. S., Thompson, A., Otaiba, S. A., Yen, L., Yang, N. J., O'Connor, R. E. (2001). Is reading important in reading-readiness programs? A randomized field trial with teachers as program implementers. Journal of Educational Psychology, 93(2), 251-267.

Fuchs, L., Fuchs, D., Hosp. M., \& Jenkins, J. (2001). Oral reading fluency as an indicator of reading competence: a theoretical, empirical, and historical analysis. Scientific Studies of Reading, 5, 239-256.

Goswami, U. (1999). Causal connections in beginning reading: The importance of rhyme. Journal of Research in Reading, 22, 217-240

Gough, P. B., \& Tunmer, W. E. (1986). Decoding, Reading, and Reading Disability. Remedial and Special Education, 7, 6-10.

Hatcher, P. J., Hulme, C., \& Ellis, A. W. (1994). Ameliorating early reading failure by integrating the teaching of reading and phonological skills: The phonological linkage hypothesis. Child Development, 65, 41-57.

Hoover, W. A., \& Gough, P. B. (1990). The simple view of reading. Reading and Writing: An Interdisciplinary Journal, 2(2), 127-160.

Janice, M. K., Anh, N. H., Chelsea, E., Meenan, B. F. Pennington, E. W. \& R. K. O. (2014) Issues in identifying poor comprehenders. L'Année psychologique, 4 (114), 753 - 777

Jiménez J. E. \& Ortiz M. R. (2000). Metalinguistic awareness and reading acquisition in the Spanish Language. Spanish Journal of Psychology, 3, 37-46. $10.1017 / \mathrm{S} 1138741600005527$

Jones, C. D., Clark, S. K., \& Reutzel, D. R. (2013). Enhancing alphabet knowledge instruction: Research implications and practical strategies for early childhood educators. Early Childhood Education Journal, 41 (2), 81-89.

Justice, L.M., Bowles, R.P., Skibbe, L. E. (2006). Measuring preschool attainment of printconcept knowledge: a study of typical and at-risk 3- to 5-year-old children using item response theory. Language, Speech, and Hearing Services in Schools, 37(3), 224-35.

Lerner, M. D., \& Lonigan, C. J. (2016). Bidirectional relations between phonological awareness and letter knowledge in preschool revisited: A growth curve analysis of the relation between two code-related skills. Journal of Experimental Child Psychology, $144,166-183$. 
Lonigan, C.J., Burgess, S.R., \& Anthony, J. L. (2000). Development of emergent literacy and early reading skills in preschool children: evidence from a latent-variable longitudinal study. Developmental Psychology, 36, 596-613.

Lundberg, I., Frost, J., \& Petersen, O.-P. (1988). Effects of an extensive program for stimulating phonological awareness in preschool children. Reading Research Quarterly, 23(3), 263-284.

Lyon G. R., Shaywitz S. E., \& Shaywitz B. A. (2003). A definition of dyslexia. Annals of Dyslexia, 53, 1-14.

Müller, B., Richter, T., Karageorgos, P., Krawietz, S., \& Ennemoser, M. (2017). Effects of a syllable-based reading intervention in poor-reading fourth-graders. Frontiers in Psychology, 8.

Nagy, W., Berninger, V., \& Abbott, R. (2006). Contributions of morphology beyond phonology to literacy outcomes of upper elementary and middle-school students. Journal of Educational Psychology. 98 (1),134-147.

National Reading Panel. (2000). Report of the National Reading Panel: Teaching children to read: An evidence-based assessment of the scientific research literature on reading and its implications for reading instruction: Reports of the subgroups. Washington, DC: National Institute of Child Health and Human Development, National Institutes of Health

O'Connor, R. E., Harty, K. R., \& Fulmer, D. (2005). Tiers of intervention in kindergarten through third grade. Journal of Learning Disabilities, 38, 532-538.

O'Connor, R. E., Jenkins, J. R., \& Slocum, T. A. (1995). Transfer among phonological tasks in kindergarten: Essential instructional content. Journal of Educational Psychology, $87(2), 202-217$.

Pennington, B. F. (1991). Diagnosing learning disorders: A neuropsychological framework. New York: Guilford Press.

Perfetti, C. A. (1985). Reading ability. New York, NY, US: Oxford University Press.

Pullen, P.C., \& Justice, L.M. (2003). Enhancing phonological awareness, print awareness, and oral language skills in preschool children. Intervention in School and Clinic, 39(2), 8798.

Saiegh-Haddad E. (2007). Linguistic constraints on children's ability to isolate phonemes in Arabic. Applied Psycholinguistics, 28 605-625. 10.1017/S0142716407070336

Saiegh-Haddad, E. (2005). Correlates of reading fluency in Arabic diglossic and orthographic factors. Reading and Writing, 18, 559-582. 
Schiff, R., Schwartz-Nahshon, S., Nagar, R. (2011). Effect of phonological and morphological awareness on reading comprehension in Hebrew-speaking adolecents with reading disabilities. Annals of Dyslexia, 61, 44-63.

Sénéchal, M., Ouellette, G., Pagan, S., \& Lever, R. (2012). The role of invented spelling on learning to read in low-phoneme-awareness kindergartners: a randomized-control-trial study. Reading and Writing, 25, 917-934.

Share, D. L. (1995). Phonological recoding and self-teaching Sine qua non of reading acquisition. Cognition, 55, 151-218.

Shaywitz, S., Morris, R., \& Shaywitz, B. (2008). The education of dyslexic children from childhood to young adulthood. Annual Review of Psychology, 59, 451-475.

Snowling M. J., Hulme C. (2011). Interventions for children's language and literacy difficulties. International Journal of Language \& Communication Disorders, 47(1), 27-34.

Snowling M. J., \& Hulme C. (2012). The nature and classification of reading disorders. A commentary on proposals for DSM-5. Journal of Child Psychology and Psychiatry, 53, 593-607. 10.1111/j.1469-7610.2011.02495.x

Snowling, M.J. (2013). Early identification and interventions for dyslexia: a contemporary view. Journal of Research in Special Educational Needs, 1, 13(1), 7-14.

Stuart, M., \& Coltheart, M. (1988) Does reading develop in a sequence of stages? Cognition, 30, 139-181

Torgesen, J., \& Mathes, P. (2000). A basic guide to understanding, assessing, and teaching phonological awareness. Austin, TX: Pro-Ed.

Torgesen, J., Morgan, S., \& Davis, C. (1992). Effects of two types of phonological awareness training on word learning in kindergarten children. Journal of Educational Psychology, 84, 364-370.

Vellutino, F. R., Scanlon, D. M., \& Lyon, G. R. (2000). Differentiating between difficult-toremediate and readily remediated poor readers: More evidence against the IQachievement discrepancy definition of reading disability. Journal of Learning Disabilities, 33, 223-238.

Wagner, R. K., Torgesen, J. K., \& Rashotte, C. A. (1994). Development of reading-related phonological processing abilities: New evidence of bidirectional causality from a latent variable longitudinal study. Developmental Psychology, 30(1), 73-87.

Zwobada, R. J. (1978). La lecture en langue arabe chez l'enfant algérien. Doctorat de 3e Cycle, Université René Descartes (268 p). 
Vellutino, F. R., Fletcher, J. M., Snowling, M. J., \& Scanlon, D. M. (2004). Specific reading disability (dyslexia): What have we learned in the past four decades? Journal of Child Psychology and Psychiatry, 45, 2-40.

Torgesen, J. K., Wagner, R. K., \& Rashotte, C. A. (1994). Longitudinal studies of phonological processing and reading. Journal of Learning Disabilities, 27(5), 276-286

Høien-Tengesdal, I., \& Tønnessen, F.-E. (2011). The relationship between phonological skills and word decoding. Scandinavian Journal of Psychology, 52, 93-103.

Wagner, R. K., Torgesen, J. K., Rashotte, C. A., Hecht, S. A., Barker, T. A., Burgess, S. R., et al. (1997). Changing relations between phonological processing abilities and word-

\begin{tabular}{|c|c|c|c|c|}
\hline \multirow{2}{*}{ Measures } & Experimental & Controls & \multirow{2}{*}{$t$ (42) Sig. } & level reading \\
\hline & $\mathrm{M} \quad(\mathrm{SD})$ & $\mathrm{M} \quad(\mathrm{SD})$ & & as children \\
\hline Age & $122.6(5.79)$ & $123.8(3.82)$ & $-.76 \mathrm{~ns}$ & develop from \\
\hline Raven & $32.32(5.23)$ & $32.41(1.18)$ & $-.08 \mathrm{~ns}$ & beginning to \\
\hline Word reading & $19.86(5.60)$ & $18.82(3.77)$ & $.65 \mathrm{~ns}$ & skilled \\
\hline Phono. awareness & $6.14 \quad(4.61)$ & $5.55(3.62)$ & $.47 \mathrm{~ns}$ & readers: a 5- \\
\hline Reading Accuracy & 7.64 (1.32) & $8.05(2.57)$ & $-.66 \mathrm{~ns}$ & year \\
\hline Reading comprehension & $1.23 \quad(0.61)$ & $1.36(0.49)$ & $-.81 \mathrm{~ns}$ & longitudinal \\
\hline
\end{tabular}

study. Developmental Psychology, 33, 468-479.

Table1. Differences between groups in pre-intervention measurements

Table2. Differences across the three times of assessment for the experimental group and the control group 


\begin{tabular}{|c|c|c|c|c|c|c|}
\hline \multirow{2}{*}{ group } & \multirow{2}{*}{ measures } & pre- (T1) & post- (T2) & follow-up (T3) & \multirow{2}{*}{$\begin{array}{l}\text { T1/T2 } \\
t \text { (Sig.) }\end{array}$} & \multirow{2}{*}{$\begin{array}{l}\text { T1/T3 } \\
t \text { (Sig.) } \\
\end{array}$} \\
\hline & & $\mathrm{M} \quad(\mathrm{SD})$ & $\mathrm{M} \quad(\mathrm{SD})$ & $\mathrm{M} \quad(\mathrm{SD})$ & & \\
\hline \multirow{3}{*}{ 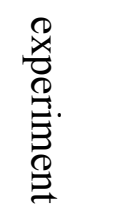 } & PA & $6.14(4.61)$ & $10.59(5.68)$ & $11.09(5.20)$ & $-2.32 *$ & $-2.71 * *$ \\
\hline & Read. acc & $7.64(1.32)$ & $9.23(1,63)$ & $10.18(2.28)$ & $-7.08 * * *$ & $-6.66 * * *$ \\
\hline & Read. comp & $1.23(0.61)$ & $1.27(1.63)$ & $1.59(0.73)$ & $-.56 \mathrm{~ns}$ & $-2.93 * *$ \\
\hline \multirow{3}{*}{$\begin{array}{l}\stackrel{8}{0} \\
\stackrel{\Xi}{0} \\
0\end{array}$} & $\mathrm{PA}$ & $5.55(3.62)$ & $5.68(4.07)$ & $5.77(3.19)$ & $-.14 \mathrm{~ns}$ & $-.28 \mathrm{~ns}$ \\
\hline & Read. acc & $8.05(2.57)$ & $7.82(2.34)$ & $8.41(1.84)$ & $.35 \mathrm{~ns}$ & $-.60 \mathrm{~ns}$ \\
\hline & Read. comp & $1.36(0.49)$ & $1.45(0.51)$ & $1.41(0.50)$ & $-.70 \mathrm{~ns}$ & $-.37 \mathrm{~ns}$ \\
\hline
\end{tabular}

Figure1. Different performances across times in the experimental group 